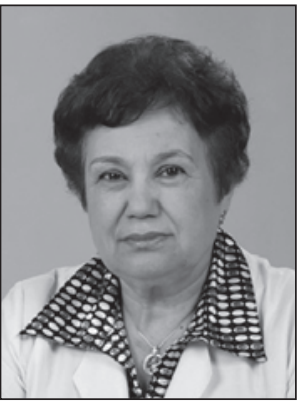

ДЕДУХН.В.,

ГУ «Институт патологии позвоночника и суставов им. проф. М.И. Ситенко НАМНУ», г. Харьков

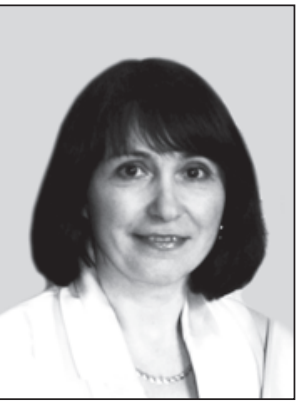

БенгуС М

\title{
МЕХАНИЗМЫ СПОНТАННОЙ РЕЗОРБЦИИ ГРЫЖИ МЕЖПОЗВОНОЧНОГО ДИСКА (Аналитический обзор литературы)
}

\section{Введение}

На этапах формирования грыжи межпозвоночного диска имеет место его пролапс - суб- или транслигаментозное выпячивание тканей диска в канал спинного мозга, то есть наблюдается локальное смещение тканей диска за пределы дискового пространства. Манифестацией процесса грыжеобразования является секвестрация грыжи с образованием свободных фрагментов, локализованных в эпидуральном пространстве канала спинного мозга. Это может приводить к тяжелым последствиям, связанным со стенозом спинномозгового канала, вплоть до параплегии.

В этих условиях неизбежно встает вопрос о возможности спонтанной резорбции грыжи диска. Спонтанная резорбция грыжи диска - это частичная или полная потеря ее объема без хирургического вмешательства. Первые наблюдения спонтанной резорбции грыжи диска были описаны в 1984-1985 гг. [1, 2].

Для изучения механизма спонтанной резорбции важной составляющей является информация о тканевом составе грыжи диска, которую можно получить с помощью магнитно-резонансной томографии (МРТ) или КТ-исследования, а также морфологического исследования послеоперационного материала.

В литературе имеются данные о структурной организации грыжевого материала и его составных частей, представленных фрагментами студенистого ядра, фиброзного кольца и гиалиновой замыкательной пластинки [3, 4]. Знание тканевого состава грыжи диска является важным для прогнозирования воспалительного ответа организма и возможности спонтанной резорбции грыжи $[3,5]$. Несмотря на то что межпозвоночный диск является аваскулярной структурой, экструзионный материал диска часто показывает наличие неоваскуляризации, что является частью естественного процесса перестройки грыжи.

В настоящем обзоре изложены вопросы, связанные с механизмами спонтанной резорбции грыжи межпозвоночного диска у экспериментальных животных с акцентом на роль в этом процессе воспаления и неоваскуляризации.

Цель работы - на основе анализа данных литературы оценить роль воспаления, неоваскуляризации, апоптоза и фагоцитоза в механизмах спонтанной резорбции грыжи межпозвоночного диска у экспериментальных животных.

\section{Воспаление в тканях межпозвоночного диска при деструкции и грыже диска}

Одной из важнейших реакций межпозвоночного диска и прилежащих паравертебральных тканей на грыжу диска является наличие воспаления в компримированной области позвоночного двигательного сегмента. Известно, что студенистое ядро при его экструзии и контакте с окружающими тканями продуцирует провоспалительные цитокины (в первую очередь ФНО- $\alpha$, а также интерлейкины), способствующие развитию воспаления в тканях, окружающих грыжу диска [6]. Это приводит к повышению сенситивности и гипералгезии нервных корешков, что сопровождается болевым синдромом.

На важную роль воспаления в диске указывают авторы, которые с помощью иммуногистохимических методов изучали клетки воспаления в экспериментальных полнослойных дефектах фиброзного кольца

(c) Дедух Н.В., Бенгус Л.М., 2013

(C) «Боль. Суставы. Позвоночник», 2013

(c) Заславский А.Ю., 2013 
свиней [7]. Скальпелем был произведен полнослойный переднелатеральный разрез фиброзного кольца длиной 10 мм в дисках $\mathrm{L}_{3}-\mathrm{L}_{4}$ или $\mathrm{L}_{4}-\mathrm{L}_{5} 12$ взрослых свиней. Иммуногистохимическими методами были проанализированы образцы ткани из области повреждения диска и смежных участков. Оказалось, что в 7 из 12 поврежденных дисков (58 \%) среди клеток воспаления преобладали макрофаги, а в 4 из 12 (33\%)Т-лимфоциты. В одном диске присутствовали единичные макрофаги, а в 4 дисках изредка обнаруживались Т-лимфоциты. В одном из 2 смежных с областью повреждения дисков было выявлено обилие макрофагов, в то время как Т-лимфоциты в нем были единичными. Эти данные послужили подтверждением того, что макрофаги могут распространяться на смежные неповрежденные участки диска. У контрольных животных в фиброзном кольце межпозвоночного диска клетки воспаления не наблюдались.

В эксперименте на собаках с аутологичной трансплантацией как студенистого ядра, так и фиброзного кольца Hasegawa et al. (2000) [8] показали, что фрагменты студенистого ядра индуцируют воспалительную реакцию. Число лимфоцитов, макрофагов и фибробластов было повышено в образцах, полученных от старых собак. Макрофаги являются наиболее типичными клетками, присутствующими в случаях как острой, так и хронической грыжи диска $[9,10]$.

Эти экспериментальные данные хорошо согласуются с клиническими наблюдениями [11-13], показавшими наличие в образцах тканей, полученных при хирургическом лечении больных с грыжей диска, клеток воспаления, преимущественно макрофагов, которые играют важную роль в процессах резорбции тканей диска. В связи с этим традиционно принято направлять терапевтические усилия на блокирование биосинтеза ФНО- $\alpha$ и других провоспалительных цитокинов для подавления воспаления.

Наличие у пациентов макрофагов в грыже диска было связано с лучшими послеоперационными результатами по сравнению с таковыми без присутствия этих клеток [14]. Воспалительная реакция, сопровождающаяся аттракцией моноцитов и формированием макрофагов, способствует успешной резорбции фрагментов грыжи диска [10, 15].

\section{Неоангиогенез в тканях межпозвоночного диска при деструкции и грыже диска}

На основе экспериментальных исследований, выполненных на белых новозеландских кроликах, были получены доказательства того, что кровеносные сосуды из окружающей грыжевый диск грануляционной ткани инфильтрируют фиброзное кольцо, но не проникают в гиалиновую хрящевую замыкательную пластинку [16]. Авторы изучали особенности неоваскуляризации в области роговицы новозеландских кроликов при имплантации в нее фрагментов (размером 4 мм), полученных из разных отделов человеческого межпозвоночного диска $\mathrm{L}_{4}-\mathrm{L}_{5}$. Было показано, что имплантация материала фиброзного кольца индуцирует прорастание сосудов в роговицу кроликов и воспалительную реакцию с последующим снижением размеров имплантата. Когда в область роговицы были имплантированы фрагменты хрящевых замыкательных пластинок, прорастание сосудов и воспаление угнетались, а имплантированный хрящевой материал не уменьшался в размерах. После одновременной имплантации в роговицу материала хрящевой замыкательной пластинки и фиброзного кольца неоваскуляризация и воспалительная реакция снижались, возможно, как результат ингибирования неоваскуляризации, свойственного хрящевой ткани [16]. Подтверждение этих данных было получено и другими авторами [17], показавшими, что одиночные свободные фрагменты грыжи диска в послеоперационном материале пациентов, содержащие гиалиновую хрящевую замыкательную пластинку, редко были окружены грануляционной тканью.

Эти данные согласуются с результатами гистопатологических исследований, показавших, что наличие гиалинового хряща в экструзионном дисковом материале может подавлять воспалительную реакцию и неоваскуляризацию, угнетая спонтанную резорбцию грыжи диска [16, 18].

К хорошо изученным стимуляторам ангиогенеза относят эндотелиальный фактор роста сосудов - VEGF (vascular endothelial growth factor). VEGF - это основной ангиогенный фактор, который является одним из представителей семейства структурно близких между собой белков, служащих лигандами для семейства рецепторов VEGF. VEGF влияет на ангиогенез и стабилизацию новообразованных кровеносных сосудов, связываясь с двумя близкими по строению мембранными тирозинкиназными рецепторами (VEGFR-1 и VEGFR-2) и активируя их [19]. Эти рецепторы экспрессируются клетками эндотелия стенки кровеносных сосудов. Связывание VEGF с этими рецепторами запускает сигнальный каскад, который в конечном итоге стимулирует рост эндотелиальных клеток сосудов in vivo, а также их выживание и пролиферацию in vitro. VEGF активирует процессы миграции и адгезии эндотелиальных клеток, а также формирование капилляроподобных структур in vitro. Таким образом, стимулируя эндотелиальные клетки, VEGF играет центральную роль в процессе ангиогенеза [19].

Синтез VEGF происходит не только в эндотелиальных клетках, но и во многих других, в том числе в фибробластах [20]. Основным клеточным источником синтеза ангиорегуляторных молекул, в том числе VEGF, являются мононуклеарные фагоциты [21]. С помощью хемоаттрактантов моноциты мигрируют в очаг повреждения, где они проявляют свою ангиорегуляторную активность. Способностью синтезировать VEGF обладают и макрофаги, причем она усиливается при различных патологических состояниях. Мононуклеарные фагоциты обладают большой пластичностью и способны по-разному реагировать на изменение микроокружения, что проявляется в разнообразии их активационных фенотипов [22]. Некоторые исследователи выделяют два типа макрофагов. Для первого 
типа макрофагов характерна цитотоксическая и противоопухолевая активность, а для второго типа - ангиогенные и противоопухолевые свойства [23].

Нейтрофилы крови человека содержат VEGF внутриклеточно и секретируют его во внеклеточное пространство в процессе дегрануляции под воздействием ФНО- $\alpha$ [24]. Имеются доказательства ангиогенной способности и биосинтеза VEGF T-лимфоцитами [19], хотя и в меньшей степени, чем макрофагами. Кроме того, известно, что не только сами Т-лимфоциты, но и их предшественники способны синтезировать VEGF. Способностью экспрессировать и-PHК VEGF обладают как тимоциты, так и стромальные клетки тимуса мышей [25].

Существует и внеклеточный пул ангиогенных молекул, фиксированных на матриксе. Находясь в комплексе с белками внеклеточного матрикса, VEGF может подвергаться действию протеолитических ферментов, которые при активации способны переводить его в свободную форму. Тканевой VEGF служит основой для развития сосудистых коллатералей при ишемическом поражении органов.

В исследованиях на 20 крысах-самцах (3-мес. животные) линии Sprague Dawley J.T. Liu и соавт. (2010) [26] была смоделирована грыжа межпозвоночного диска. Хирургическим путем были извлечены каудальные межпозвоночные диски из хвостового отдела позвоночника и имплантированы в эпидуральное пространство на уровне $\mathrm{L}_{5}$. Через 30 дней после операции извлекали имплантированное студенистое ядро для гистологической и иммуногистохимической оценки, а также исследования клеток с помощью жидкостной цитофлюорометрии. Контрольной группе животных в область паравертебральных мышц был имплантирован виток ниток. В опытной группе животных на 30-й день после операции была обнаружена положительная иммуногистохимическая реакция на эндотелиальный фактор роста сосудов VEGF и фактор некроза опухоли $\alpha$, а также было обнаружено статистически достоверное увеличение количества Т- и В-лимфоцитов. Данная модель хорошо отражает воспалительные процессы, имеющие место в поврежденном диске.

H. Haro (2002) и соавт. [27] показали, что VEGF и его рецепторы VEGFR-1 и VEGFR-2 экспрессируются в образцах грыжи межпозвоночного диска человека, полученных после хирургического лечения. Острую фазу грыжи диска моделировали, используя культуру мышиных перитонеальных макрофагов и ткани межпозвоночного диска. В макрофагах под влиянием ткани диска было отмечено повышение экспрессии белка VEGF и его и-РНК. Индукция VEGF имела место в присутствии ФНО- $\alpha$. На основании этого авторы заключают, что VEGF индуцирует ангиогенез в грыжевом диске, тем самым способствуя его резорбции.

Особенности кровоснабжения играют существенную роль в процессах грыжеобразования и последующей перестройки грыжи диска. Оказалось, что в случае интенсивной васкуляризации в области грыжи диска его спонтанная резорбция макрофагами является более выраженной, чем при наличии низкого уров- ня кровоснабжения. Поэтому для пациентов с высокой васкуляризацией предпочтительным способом лечения грыжи диска является консервативное лечение [28], в то время как больным с низкой васкуляризацией показано хирургическое вмешательство.

\section{Молекулярные механизмы спонтанной резорбции грыжи межпозвоночного диска}

В настоящее время появляются работы, которые затрагивают глубинные механизмы спонтанной резорбции грыжи диска - на уровне цитокинов и факторов роста.

В процесс спонтанной резорбции грыжи диска могут быть вовлечены и сигнальные молекулы, отвечающие за клеточную гибель, в частности Fas-лиганд, являющийся триггером апоптоза в клетках студенистого ядра [29-31]. В культуре клеток студенистого ядра крысы было установлено, что Fas-лиганд может не только индуцировать апоптоз хондроцитов в межпозвоночном диске, но и выступать в роли воспалительного агента [32].

Исследование, выполненное на крысах, показало увеличение экспрессии IL-1 $\beta$, IL-6 и синтеза оксида азота в нервных корешках и дорсальных ганглиях через 1 неделю после имплантации фрагментов аутологичного студенистого ядра [33]. Дальнейшее прогрессирование воспалительного процесса может быть обусловлено влиянием IL-1 $\beta$ : добавление этого цитокина к ткани нормального диска in vitro вызывает повышение продукции IL-6, оксида азота, PGE-2 и металлопротеиназ [34].

A. Minamide (1999) [35] отметил важную роль в процессе спонтанной резорбции грыжи межпозвоночного диска фактора роста фибробластов (FGF- $\beta)$, одним из аспектов воздействия которого является стимуляция ангиогенеза in vivo. В экспериментальной модели на кроликах, имитирующей секвестрацию грыжи межпозвоночного диска, было показано, что аутологичный материал межпозвоночного диска $\mathrm{L}_{1}-\mathrm{L}_{2}$, помещенный в заднее эпидуральное пространство на уровне позвонка $\mathrm{L}_{4}$, был пенетрирован новообразованными сосудами, формирующимися из эпидуральной жировой ткани. Это свидетельствует о том, что ткань диска, находящаяся в нетипичном для нее месте, уже самостоятельно индуцирует ангиогенез. Затем авторы выясняли, каким образом этот процесс можно ускорить. Для этого 36 кроликов были подразделены на 3 группы. У всех кроликов производили частичное иссечение межпозвоночного диска $\mathrm{L}_{1}-\mathrm{L}_{2}$, при этом иссеченный материал содержал фрагмент студенистого ядра и фиброзного кольца. Перед аутотрансплантацией в эпидуральное пространство $\mathrm{L}_{4}$ этот материал погружали на 2 часа в три разных по составу раствора: в контрольной группе - в физиологический раствор, в двух опытных группах - в растворы, содержащие FGF- $\beta$, в концентрациях 5 мг/мл и 20 мг/мл соответственно. Через 1 и 2 недели после операции в группах животных, получивших обработку FGF- $\beta$, в области аутотрансплантации новообразованные сосуды при- 
сутствовали в большем количестве, чем в контроле, при этом в опытных группах также было увеличено количество макрофагов, лимфоцитов и фибробластов. Уменьшение размеров трансплантированного материала межпозвоночного диска было более выражено у животных, получивших высокую дозу (20 мг/мл) FGF- $\beta$. Таким образом, авторы доказали, что фактор роста фибробластов стимулирует формирование новых сосудов в материале межпозвоночного диска, помещенном в эпидуральное пространство, что способствует частичной резорбции грыжи диска.

Сами хондроциты дегенеративно измененного диска начинают продуцировать провоспалительные цитокины (фосфолипазу $\mathrm{A}_{2}$, IL-1, IL-2, IL-6, ФНО- $\alpha$ и оксид азота), которые путем ауто- и паракринного воздействия индуцируют биосинтез простагландинов (ПГ) - медиаторов воспаления (главным образом ПГЕ ${ }_{2}$ [36-38]. Эти медиаторы стимулируют высвобождение металлопротеиназ, которые играют основную роль в дегенерации межпозвоночного диска [36].

Важным моментом, дающим объяснение того, каким образом может осуществляться спонтанная резорбция грыжи диска, является тот факт, что клетки грыжи являются более чувствительными к информационным сигналам, чем клетки нормальных дисков, и продуцируют в огромном количестве металлопротеиназы [39], способствующие разрушению хрящевого матрикса. Высвобождение матриксных металлопротеиназ (ММР-3 и ММР-7 - ферментов, играющих ключевую роль в каскаде деградации хрящевого матрикса) способствует спонтанной резорбции диска $[11,40]$.

Как известно, гиалиновый хрящ, являясь аваскулярной тканью, имеет антиангиогенную активность, тесно связанную с антипротеолитической активностью, которая осуществляется тканевыми ингибиторами матриксных металлопротеиназ (TIMPs) или присутствием аггрекана [41]. В связи с тем, что многие матриксные металлопротеиназы, особенно желатиназы и мембраносвязанная матриксная металлопротеиназа-1 (ММР-1), вовлечены в миграцию эндотелиальных клеток и формирование капилляров, ингибирование матриксных металлопротеиназ (MMPs) тканевыми ингибиторами металлопротеиназ может предотвращать ангиогенез [42]. Антиангиогенная активность TIMPs зависит от их способности ингибировать матриксные металлопротеиназы. ТІМР-3, являясь мощным ингибитором ангиогенеза, связывается непосредственно с VEGF рецептором-2 и блокирует действие VEGF на эндотелиальные клетки [43]. TIMРs ингибируют активацию эндотелиальных клеток и способствуют формированию у них периода покоя [44]. С учетом этого становится понятным, почему наличие фрагментов гиалиновой замыкательной пластинки (обладающей антиангиогенной и антипротеолитической активностью) в грыже диска угнетает неоангиогенез и спонтанную резорбцию грыжи.

Интересные данные о механизмах спонтанной резорбции грыжи диска были представлены W. Meng и соавт. (2001) [45]. Авторы воспроизводили на крысах модель грыжи диска путем подкожной транспланта- ции в область спины животных аутологичных межпозвоночных дисков из хвостового отдела позвоночника. С помощью иммуногистохимических методов было показано, что в самые ранние сроки после аутотрансплантации (на 1-2-й день) в клетках межпозвоночного диска наблюдалось выраженное повышение экспрессии катепсинов G и L (сериновых и цистеиновых протеиназ соответственно), которые, как оказалось, также вовлечены в процесс спонтанной резорбции диска как матрикс-деградирующие энзимы. Кроме того, роль этих катепсинов в каскаде реакций спонтанной резорбции имплантированного под кожу диска заключается в активации ими латентных проэнзимов (прометаллопротеиназ ММР-1 и ММР-3). Отмеченная авторами солокализация катепсина $\mathrm{G}$, MМР-1 и ММР-3 в клетках аутотрансплантированного диска указывает на то, что катепсин G способствует активации MMPs и инактивации их ингибиторов (TIMPs), приводя к макрофагозависимой деградации внеклеточного матрикса.

Следует отметить, что в отличие от инфильтрации макрофагами, которая имела место спустя два дня после аутотрансплантации, выраженная экспрессия катепсинов $\mathrm{G}$ и $\mathrm{L}$ обнаруживалась уже на 1-2-й день посттрансплантационного периода. Это свидетельствует о том, что катепсины продуцируются клетками диска независимо от макрофагальной инфильтрации в отличие от MMPs, которые имеют макрофагозависимое повышение экспрессии. Эти исследования показали, что ранняя экспрессия катепсинов в клетках диска активируется до начала макрофагозависимых процессов его резорбции. В дальнейшем имеет место макрофагальная инфильтрация и активация про-MMPs, секретируемых в результате индукции макрофагов [45].

На рис. 1 схематически представлены молекулярные механизмы, вовлеченные в возможный процесс спонтанной резорбции грыжи диска.

\section{Активизация аутоиммунной реакции при грыже диска}

Согласно данным разных авторов [46-49] в процессе формирования грыжи диска важную роль играет иммунный ответ организма. Существует тесная связь между процессами ангиогенеза и воспаления при непосредственном участии в них реакций врожденного иммунитета [50]. Рост сосудов происходит на фоне воспаления и лейкоцитарной инфильтрации. Клетки иммунной системы продуцируют VEGF и являются регуляторами ангиогенеза [19].

Известно, что аутологичные ткани организма не распознаются его иммунной системой как инородное тело. Студенистое ядро является иммунопривилегированной тканью, изолированной от иммунной системы [51], которая, подобно другим изолированным тканям, включающим глаз и яички, может продуцировать воспалительный аутоиммунный ответ [52]. Возможным триггером для активизации аутоиммунной реакции может быть сам врожденный иммунитет, индуцируемый химическими факторами (без специфического ответа «антиген - антитело»). Поскольку клетки сту- 


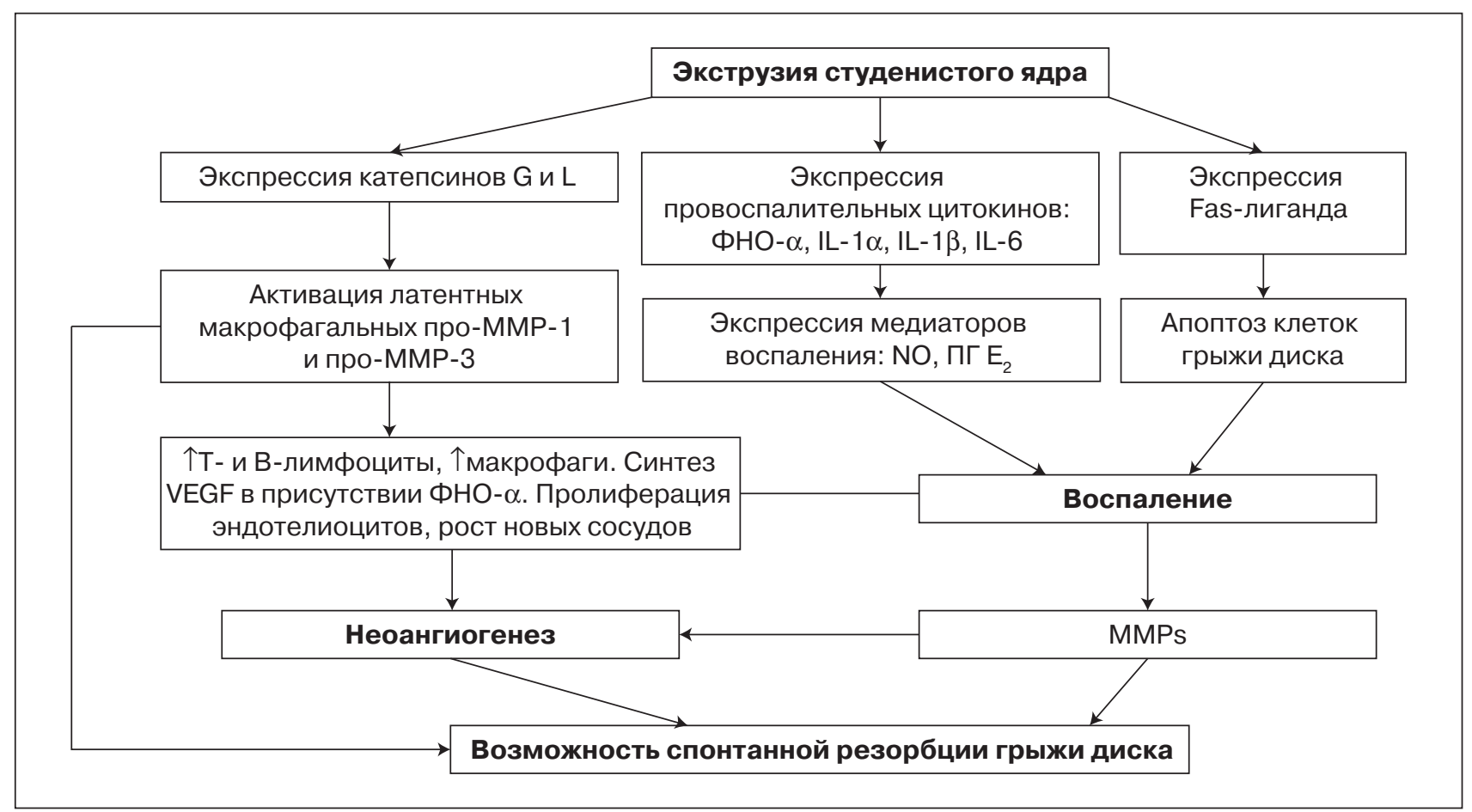

Рисунок 1. Молекулярные механизмы возможной спонтанной резорбции грыжи межпозвоночного диска

денистого ядра продуцируют химические факторы, а изменение структуры внеклеточного матрикса, вызываемое клетками студенистого ядра, может имитировать действие патологических микробных антигенов, то студенистое ядро может быть триггером врожденного иммунного ответа [53].

K. Murai и соавт. (2010) [49] установили, что иммунный ответ вызывает даже интактное студенистое ядро, не имеющее признаков дегенерации. Подкожная трансплантация аутологичного студенистого ядра из межпозвоночного диска хвостового отдела позвоночника у крыс дикого типа, а также у мышей с иммунодефицитом показала значительно большее выживание клеток студенистого ядра у иммунодефицитных мышей. Иммуногистохимическое окрашивание позволило выявить в трансплантированном студенистом ядре присутствие макрофагов и Т-лимфоцитов.

В исследованиях in vitro у крыс было показано ингибирование формирования колоний аутологичных клеток студенистого ядра аутологичными иммунными клетками селезенки, а также доказан цитотоксический эффект Т-лимфоцитов и макрофагов на клетки студенистого ядра [49]. Эти исследования продемонстрировали, что студенистое ядро само по себе уже распознается иммунокомпетентными клетками как инородный материал, вызывающий активизацию иммунного ответа.

В научной литературе также имеются данные об активизации аутоиммунной реакции организма в ответ на грыжу диска. Известно, что после завершения эмбрионального развития студенистое ядро не содержит сосудов и не взаимодействует с иммунной системой. Однако из грыжевого материала, особенно секвестрированного, могут высвобождаться вещества, индуцирующие аутоиммунный ответ, который может вызывать хроническое воспаление [46, 54]. Студенистое ядро животных и человека имеет антигенные свойства $[47,48]$. В сыворотке крови человека и у животных моделей были обнаружены антитела к студенистому ядру $[54,55]$. Эпидуральная инъекция студенистого ядра у собак вызывает воспалительную реакцию с формированием гранулем [56]. У кроликов после инъекции студенистого ядра было выявлено образование аутоантител [55].

H. Brisby и соавт. (2002) [57] обнаружили, что у 2/3 пациентов с дегенерацией межпозвоночных дисков поясничного отдела позвоночника и наличием радикулярных симптомов в сыворотке крови имелось увеличенное количество циркулирующих аутоантител к гликосфинголипидам. Известно, что титр антител к гликосфинголипидам повышен у пациентов с аутоиммунными неврологическими заболеваниями, такими как демиелинизирующая полинейропатия. Выявление таких аутоантител у пациентов с дегенеративными заболеваниями межпозвоночных дисков указывает на наличие у них аутоиммунного компонента. Другие авторы иммуногистохимическими методами обнаружили присутствие у пациентов с грыжей диска поясничного отдела позвоночника наличие антител к специфическим антигенам студенистого ядра, формирующих комплекс «антиген - антитело», локализованный в перицеллюлярном пространстве клеток грыжи диска [47].

Несмотря на эти данные, мнение о том, что при дегенерации межпозвоночных дисков поясничного отдела позвоночника имеет место аутоиммунный ответ, является противоречивым. Некоторые исследователи показали отсутствие в грыжах диска клеток воспаления (Т-лимфоцитов и макрофагов), которые вовлечены в антигенспецифический ответ [7]. В хирургиче- 
ском материале пациентов с грыжей диска поясничного отдела позвоночника не было обнаружено экспрессии иммунофенотипических маркеров лимфоцитов (CD20, CD45, CD4, CD8) и зрелых моноцитов (CD33) [58, 59]. По мнению J.B. Park (2001) [29] и Р. Jones (2008) [60], клетки студенистого ядра в грыжах диска подвергаются апоптозу и фагоцитируются макрофагами без активизации иммунного ответа.

\section{Активизация апоптоза и фагоцитоза при грыже диска}

Следует отметить, что в грыжах диска, так же как и в дегенеративно измененных дисках [29, 32, 61, 62], имеет место активизация апоптоза хондроцитов [30, 63]. Так, было установлено, что хондроциты в экструзионном материале диска и в секвестрированных фрагментах грыжи диска [29] гибнут путем апоптоза и этот процесс сопряжен с аутокринной либо паракринной экспрессией Fas-лиганда самими клетками диска [30].

L. Zhang и соавт. (2008) [63] с помощью иммуногистохимического анализа экспрессии рецепторов клеточной гибели DR-4 (death receptor-4 - член суперсемейства ФНО) в 60 хирургических образцах грыжи межпозвоночного диска обнаружили преобладание апоптотических клеток в студенистом ядре по сравнению с фиброзным кольцом. Причем в грыжевых образцах апоптотических клеток было значительно больше, чем в нормальных дисках. В грыжевом материале была выявлена мощная экспрессия рецепторов смерти DR-4, а процент апоптотических клеток коррелировал с выраженностью дегенерации диска, что позволило авторам сделать заключение о важной роли молекулярной пары «рецептор смерти DR-4 и его лиганд TRAIL» (TNF-related apoptosis-inducing ligand) в апоптозе грыжевых дисков.

Оказалось, что активизация апоптоза в хондроцитах, присутствующих в грыжах диска, так же, как и воспаление, способствует спонтанной резорбции грыжевых масс [60]. В связи с тем что межпозвоночный диск млекопитающих является аваскулярной структурой в организме [64], элиминация апоптотических клеток в нем не может осуществляться с помощью коммитированных фагоцитов - макрофагов. При отсутствии специализированных макрофагов способность к фагоцитозу апоптотических клеток могут приобретать фибробласты, эндотелиальные клетки и даже хондроциты [65-67].

В научной литературе установилось прочное мнение о том, что функция хондроцитоподобных клеток студенистого ядра [68] межпозвоночного диска (которыми представлено зрелое студенистое ядре взрослого человека и некоторых видов животных, например кроликов и гончих собак) [69] заключается только в продукции хрящевого матрикса. Но в настоящее время эти данные пересматриваются. Оказалось, что хондроцитоподобные клетки студенистого ядра могут трансформироваться в фагоциты $[60,70]$. Это указывает на то, что неотъемлемым элементом развития науки является сомнение и периодическое опровержение казавшихся ранее незыблемыми постулатов.
В исследовании Р. Jones (2008) [60] при культивировании клеток студенистого ядра из каудальных межпозвоночных дисков быка с помощью методов флюоресцентной микроскопии и микроскопического видеонаблюдения было показано, что клетки студенистого ядра фагоцитировали латексные частицы, добавленные в культуральную среду. Причем количество частиц латекса, фагоцитированных клетками студенистого ядра, было больше поглощенного сокультивируемыми специализированными фагоцитами. Этот факт авторы связывают с тем, что клетки студенистого ядра имеют большие размеры, чем коммитированные фагоциты. Кроме того, в монослойной культуре при сокультивировании клеток диска с облученными ультрафиолетом опухолевыми клетками HeLa (для индукции в них апоптоза) хондроцитоподобные клетки студенистого ядра приобретали способность фагоцитировать апоптотические клетки. На основании этого авторы делают вывод о том, что апоптотические клетки диска, присутствующие в нем in vivo на этапах его дегенерации и в грыжах диска, посылают сигналы, которые стимулируют процесс фагоцитоза жизнеспособными клетками диска. Триггером фагоцитоза специализированных фагоцитов является экспрессируемый на наружной мембране апоптотических клеток фосфатидилсерин, который связывается с рецепторами клеточной смерти (CD36, CD68, CD14). При этом менее известен молекулярный каскад, который имеет место у факультативных фагоцитов, к которым относятся и хондроцитоподобные клетки диска [66, 71]. Полагают, что для активизации факультативных фагоцитов и вовлечения их в фагоцитоз апоптотических клеток более важны лектины [65]. В исследованиях $[60,70]$ были получены убедительные доказательства того, что клетки студенистого ядра диска могут вести себя как фагоциты, а также подвергаться фагоцитозу после апоптоза. Хондроциты суставного [67] и эпифизарного хряща [72] также могут становиться факультативными фагоцитами. Механизм активации факультативных фагоцитов необходим для элиминации апоптотических клеток в дегенеративно измененном межпозвоночном диске. Гибель клеток, нарушение организации матрикса способствуют формированию очагов некроза в тканях диска и развитию в нем воспаления [73].

Существует распространенное мнение о том, что грыжа диска резорбируется с помощью моноцитопосредованного фагоцитоза [38, 74, 75]. Однако до настоящего времени неизвестно, каким образом запускается процесс хемотаксиса моноцитов, т.е. что является его триггером. Для выяснения точного механизма хемотаксиса макрофагов на ранней стадии формирования грыжи диска в экспериментальной модели на крысах иммуногистохимическими методами был исследован мощный хемоаттрактант макрофагов - моноцитарный хемоаттрактантный белок 1 [76]. В брюшную полость крыс линии Вистар были имплантированы аутологичные межпозвоночные диски хвостового отдела позвоночника. На 2, 3, 
7 и 14-й дни после имплантации диски были изучены с помощью иммуногистохимических методов, после чего был произведен количественный анализ моноцитарного хемоаттрактантного белка 1 с применением многослойного иммуноферментного метода. На 3-й день после имплантации вокруг межпозвоночного диска наблюдались гранулоциты и макрофаги с положительной реакцией на моноцитарный хемоаттрактантный белок 1. При этом совершенно неожиданным было выявление в студенистом ядре и во внутренних отделах фиброзного кольца хондроцитов с аналогичной положительной реакцией. На 7-й день в грануляционной ткани области имплантации появлялись макрофаги с положительной реакцией на моноцитарный хемоаттрактантный белок-1. Некоторые из этих клеток внедрялись в студенистое ядро и внутренние отделы фиброзного кольца имплантированных дисков. Это позволило автору сделать вывод о том, что хондроциты дегенеративного межпозвоночного диска стимулируют хемотаксис моноцитов, принимающих участие в резорбции диска и играющих важную роль в пополнении их пула. Таким образом хондроциты опосредованно способствуют спонтанной резорбции экспериментально смоделированной грыжи диска.

Исследования по изучению роли моноцитарного хемоаттрактантного белка 1 в раннем механизме спонтанной резорбции грыжи диска были продолжены M. Yoshida (2005) [77] на кроликах. Иммуногистохимическими методами авторы изучали экспрессию этого хемокина, а также фактора некроза опухоли $\alpha$ и интерлейкина- $1 \beta$. Клетки межпозвоночного диска грыжевых дисков на первый день после операции продуцировали фактор некроза опухоли $\alpha$ и интерлейкин $1 \beta$, а на третий день - моноцитарный хемоаттрактантный белок 1. На третий день после операции была отмечена инфильтрация области грыжи диска макрофагами. Было установлено, что через 12 недель после экспериментального моделирования грыжи диска имело место уменьшение ее размеров. На основании этого авторы сделали заключение, что клетки межпозвоночного диска могут сразу же после формирования грыжи диска продуцировать цитокины/хемокины, запускающие макрофагальную инфильтрацию, что способствует активизации спонтанной резорбции грыжевого образования.
На рис. 2 схематически представлены ключевые механизмы, вовлеченные в процесс возможной спонтанной резорбции грыжи межпозвоночного диска.

Таким образом, индукция патологического апоптоза в клетках межпозвоночного диска, активизация фагоцитарных свойств хондроцитоподобных клеток студенистого ядра, воспаление и неоваскуляризация в области грыжевого диска отражают адаптационно-компенсаторные механизмы организма, имеющие место при дегенерации и грыже межпозвоночного диска.

\section{Заключение}

В патогенезе грыжи межпозвоночного диска важную роль играют процессы активизации локальной воспалительной реакции, неоангиогенез и аутоиммунный ответ организма. При грыже также имеет место активизация апоптоза и фагоцитоза в клетках диска. С наступлением эпохи визуализации изображений всех органов и тканей организма (KT, MPT) повышается интерес к феномену спонтанной резорбции грыжи межпозвоночного диска. Становится возможным постепенное раскрытие уникальных патофизиологических механизмов этого процесса. Гистологические исследования показали, что грыжа межпозвоночного диска окружена грануляционной тканью, инфильтрированной клетками воспаления, имеющей признаки неоваскуляризации. В феномене спонтанной резорбции грыжевого диска могут играть роль различные факторы. Главными из них являются неоангиогенез, клетки воспаления и провоспалительные цитокины. Индукция неоангиогенеза и спонтанная резорбция грыжи диска происходят на фоне усиления продукции VEGF, IL-1 $\beta$, матриксных металлопротеиназ ММР-3 и ММР-7, повышения экспрессии катепсинов $\mathrm{G}$ и L, активизирующих латентные проэнзимы ММР и подавляющих биосинтез тканевых ингибиторов металлопротеиназ. Стимулятором ангиогенеза также является фактор роста фибробластов, активизирующий процессы митогенеза и хемотаксиса эндотелиальных клеток капилляров и фибробластов. Данные, полученные при изучении процесса спонтанной резорбции грыжи межпозвоночного диска в экспериментах на животных, в будущем, возможно, могут быть использованы в клинической практике.

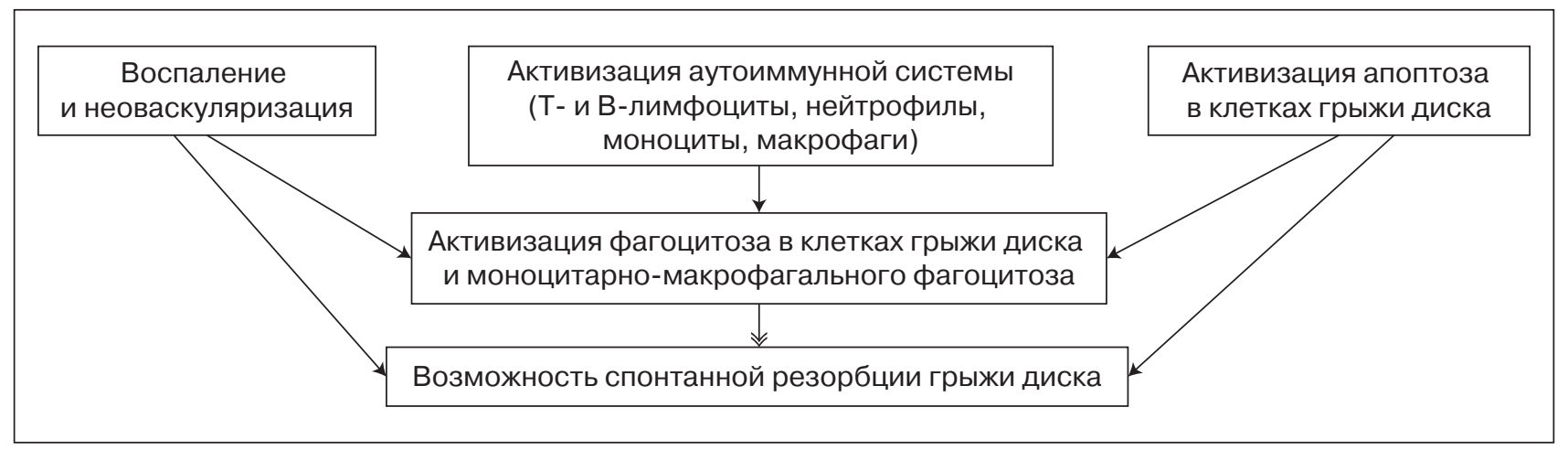

Рисунок 2. Ключевые механизмы возможной спонтанной резорбции грыжи межпозвоночного диска 


\section{Список литературы}

1. Guinto F.C., Hashim H., Stumer M. CT demonstration of disk regression after conservative therapy / F.C. Guinto, H. Hashim, M. Stumer // Am. J. Neuroradiol. - 1984. Vol. 5. - P. 632-633.

2. Teplick J.G. Spontaneous regression of herniated nucleus pulposus / J.G. Teplick, M.E. Haskin // Am. J. Roentgenol. - 1985. - Vol. 145. - P. 371-375.

3. Brock M. The form and structure of the extruded disc/ M. Brock, S. Patt, H.M. Mayer // Spine. - 1992. - Vol. 17. P. 1457-1461.

4. The origin and fate of herniated lumbar intervertebral disc tissue / R.J. Moore, B. Vernon-Roberts, R.D. Fraser, M. Schembri // Spine. - 1996. - Vol. 21. - P. 2149-2155.

5. Histologic changes in the disc after cervical spine trauma: evidence of disc absorption / L.Y. Carreon, T. Ito, M. Yamada et al. // J. Spinal. Disord. - 1996. - Vol. 9. - P. 313-316.

6. Экспериментальные аспекты моделирования грыжи межпозвоночного диска (аналитический обзор литературы) / В.О. Радченко, Н.В. Дедух, Л.М. Бенгус, М.В. Шимон // Боль, суставы, позвоночник. - 2011. - № 2. - С. 88-93.

7. Inflammatory cells in full-thickness anulus injury in pigs. An experimental disc herniation animal model / A. Habtemariam, J. Virri, M. Gronblad et al. // Spine. - 1998. - Iss. 1. Vol. 23. - № 5. - P. 524-529.

8. The effect of age on inflammatory responses and nerve root injuries after lumbar disc herniation: an experimental study in a canine model / T. Hasegawa, H.S. An, A. Inufusa et al. // Spine. - 2000. - Vol. 25. - P. 937-940.

9. Pathomechanism of spontaneous regression of herniated lumbar disc: histologic and immunohistochemical study / T. Ikeda, T. Nakamura, T. Kikuchi et al. // J. Spinal. Disord. - 1996. - Vol. 9. - P. 136-140.

10. A comparative immunohistochemical study of inflammatory cells in acute-stage and chronic-stage disc herniations / A. Habtemariam, M. Gronblad, J. Virri et al. // Spine. - 1998. - Vol. 23. - P. 2159-2166.

11. Matrix metalloproteinase-7-dependent release of a tumor necrosis factor-a in a model of herniated disc resorption / H. Haro, H.C. Crawford, B. Fingleton et al. / J. Clin. Invest. - 2000. - Vol. 105. - P. 143-50.

12. Chemokine profile of herniated intervertebral discs infiltrated with monocytes and macrophages / S. Kawaguchi, T. Yamashita, G. Katahira et al. // Spine (Phila Pa 1976). 2002. - Vol. 27. - № 14. - P. 1511-1516.

13. Podichetty V.K. The aging spine: the role of inflammatory mediators in intervertebral disc degeneration / V.K. Podichetty // Cell Mol. Biol. - 2007. - Vol. 53, № 5. - P. 4-18.

14. Woertgen C. Influence of macrophage infiltration of herniated lumbar disc tissue on outcome after lumbar disc surgery / C. Woertgen, R.D. Rothoerl, A. Brawanski // Spine. 2000. - Vol. 25. - P. 871-875.

15. Intervertebral disc cells produce tumor necrosis factor alpha, interleukin-1beta, and monocyte chemoattractant protein-1 immediately after herniation: an experimental study using a new hernia model / M. Yoshida, T. Nakamura, A. Sei et al. // Spine. - 2005. - Vol. 30. - № 1. - P. 55-61.

16. Neovascularization induced by anulus and its inhibition by cartilage endplate: its role in disc absorption / L.Y. Carreon, T. Ito, M. Yamada et al. // Spine. - 1997. - Vol. 22. - P. 1429-1434.

17. Brock M. The form and structure of the extruded disc // M. Brock, S. Patt, H.M. Mayer // Spine. - 1992 . Vol. 17. - P. 1457-1461.

18. Pathomechanism of spontaneous regression of herniated lumbar disc: histologic and immunohistochemical study / T. Ikeda, T. Nakamura, T. Kikuchi et al. // J. Spinal. Disord. - 1996. - Vol. 9. - P. 136-140.

19. Фактор роста сосудистого эндотелия и иммунная система / Е.П. Киселева, А.В. Крылов, Э.А. Старикова, С.А. Кузнецова // Успехи современной биологии. 2009. - T. 129, № 4. - C. 1-12.

20. Expression of vascular endothelial growth factor in synovial fibroblasts is induced by hypoxia and interleukin 1?/
J.R. Jackson, J.A. Minton, M.L. Ho et al. // J. Rheumatol. 1997. - 24. - P. 1253-1259.

21. Moldovan L. Role of monocytes and macrophages in angiogenesis / L. Moldovan, N.I. Moldovan // Mechanisms of angiogenesis. - 2005. - Vol. 94. - P. 127-146.

22. Старикова Э.А. Гетерогенность мононуклеарных фагоцитов: субпопуляции или проявления пластичности / Э.А. Старикова, Е.П. Киселева, И.С. Фрейдлин // Успехи современной биологии. - 2005. - Т. 125, № 5. C. 466-477.

23. Tumour-associated macrophages are a distinct M2 polarised population promoting tumour progression: potential targets of anti-cancer therapy / A. Sica, T. Schioppa, A. Mantovani, P. Allavena // Eur. J. Cancer. - 2006. - Vol. 42, № 6. - P. 717-727.

24. Intracellular pool of vascular endothelial growth factor in human neutrophils / M. Gaudry, O. Bregerie, V. Andrieu et al. // Blood. - 1997. - Vol. 90. - P. 4153-4161.

25. Экспрессия генов VEGF-A и VEGF-C и их рецепторов в лимфоцитах и макрофагах мышей / О.И. Степанова, А.В. Крылов, В.И. Людыно, Е.П. Киселева // Биохимия. - 2007. - Т. 72, № 11. - С. 1468-1473.

26. Liu J.T. A study of a rat lumbar disc herniation model and the mechanism spontaneous of resorption / J.T. Liu, H. Jiang, Y.J. Wang et al. // Zhongguo Gu Shang. - 2010. Vol. 23, № 5. - P. 370-372.

27. Vascular endothelial growth factor (VEGF)-induced angiogenesis in herniated disc resorption / H. Haro, T. Kato, H. Komori et al. // J. Orthop. Res. - 2002. - Vol. 20. P. 409-415.

28. Lumbar Disk Herniation: Correlation of Histologic Findings with Marrow Signal Intensity Changes in Vertebral Endplates at MR Imaging / G. Schmid, A. Witteler, R. Willburger et al. // Radiology. - 2004. - Vol. 231. - P. 352-358.

29. Expression of Fas-receptor on disc cells in herniated lumbar disc tissue / J.B. Park, K.W. Kim, C.W. Han et al. // Spine. - 2001. - Vol. 26. - P. 142-146.

30. Park J.B. Expression of fas ligand and apoptosis of disc cells in herniated lumbar disc tissue / J.B. Park, H.K. Chang, Ki-Won // Spine. - 2001. - Vol. 26, Iss. 6. - P. 618-621.

31. Chowdhury I. Current concepts in apoptosis: the physiological suicide program revisited / I. Chowdhury, B. Tharakan, G.K. Bhat // Cell Mol. Biol. Lett. - 2006. - Vol. 11. P. 506-525.

32. Double role of Fas ligand in the apoptosis of intervertebral disc cells in vitro / D. Han, Y. Ding, S.-L. Liu et al. // Acta Biochim. Biophys. Sin. - 2009. - Vol. 4, Iss. 11. - P. 938-947.

33. mRNA expression of interleukins, phospholipase A2, and nitric oxide synthase in the nerve root and dorsal root ganglion induced by autologous nucleus pulposus in the rat / $\mathrm{M}$. Kawakami, T. Matsumoto, K. Kuribayashi et al. // J. Orthop. Res. - 1999. - Vol. 17. - P. 941-946.

34. Toward a biochemical understanding of human intervertebral disc degeneration and herniation. Contributions of nitric oxide, interleukins, prostaglandin E2, and matrix metalloproteinases / Kang J.D., Stefanovic-Racic M., McIntyre L.A. et al. // Spine. - 1997. - Vol. 22. - P. 1065-1073.

35. Effects of Basic Fibroblast Growth Factor on Spontaneous Resorption of Herniated Intervertebral Discs: An Experimental Study in the Rabbit / A. Minamide, H. Hashizume, M. Yoshida et al. // Spine. - 1999. - Vol. 24, Iss. 10. P. 940-945.

36. The role of inflammation in disk herniation-associated radiculopathy / P. Goupille, M.I. Jayson, J.P. Valat, A.J. Freemont // Semin. Arthritis Rheum. - 1998. Vol. 28. - P. 60-71.

37. mRNA expression of cytokines and chemokines in herniated lumbar intervertebral discs / Ahn S.H., Cho Y.W., Ahn M.W. et al. // Spine. - 2002. - Vol. 27. - P. 911-917.

38. Spontaneous production of monocyte chemoattractant protein-1 and interleukin- 8 by the human lumbar intervertebral disc / J.G. Burke, R.W. Watson, D. McCormack et al. // Spine (Phila Pa 1976). - 2002. - Vol. 27, № 13. - P. 1402-1407. 
39. Histology and Pathology of the Human Intervertebral Disc / S. Roberts, H. Evans, J. Trivedi et al. // Journal of Bone and Joint Surgery. - 2006. - Vol. 88, Suppl. 2. - P. 10-14.

40. Sequential dynamics of inflammatory cytokines, angiogenesis inducing factor and matrix degrading enzymes during spontaneous resorption of the herniated disc / T. Kato, H. Haro, H. Komori, K. Shinomiya // J. Orthop. Res. - 2004. Vol. 22, № 4. - P. 895-900.

41. Brew K. The tissue inhibitors of metalloproteinases (TIMPs): An ancient family with structural and functional diversity / K. Brew, H. Nagase // Biochim. Biophys. Acta. 2010. - Vol. 1803, № 1. - P. 55-71.

42. Handsley M.M. Metalloproteinases and their inhibitors in tumor angiogenesis / M.M. Handsley, D.R. Edwards // Int. J. Cancer. - 2005. - Vol. 115. - P. 849-860.

43. A novel function for tissue inhibitor of metalloproteinases-3 (TIMP3): inhibition of angiogenesis by blockage of VEGF binding to VEGF receptor-2 / J.H. Qi, Q. Ebrahem, N. Moore et al. // Nat. Med. - 2003. - Vol. 9. - P. 407-415.

44. Coregulation of vascular tube stabilization by endothelial cell TIMP-2 and pericyte TIMP-3 / W.B. Saunders, B.L. Bohnsack, J.B. Faske et al. // J. Cell Biol. - 2006. Vol. 175. - P. 179-191.

45. Localization of cathepsins $\mathrm{G}$ and $\mathrm{L}$ in spontaneous resorption of intervertebral discs in a rat experimental model / W. Meng, K. Yonenobu, K. Ariga et al. // J. Musculoskel. Neuron. Interact. - 2001. - Vol. 2, № 2. - P. 171-176.

46. Gertzbein S.D. The stimulation of lymphocytes by nucleus pulposus in patients with degenerative disk disease of the lumbar spine / S.D. Gertzbein, J.H. Tait, S.R. Devlin // Clin. Orthop. - 1977. - Vol. 123. - P. 149-54.

47. Presence and distribution of antigen-antibody complexes in the herniated nucleus pulposus / K. Satoh., S. Konno, K. Nishiyama et al. // Spine. - 1999. - Vol. 24. - P. 19801984.

48. Pathophysiology of disk-related sciatica. I. - Evidence supporting a chemical component. Review / D. Mulleman, S. Mammou, I. Griffoul et al. // Joint Bone Spine. - 2006. Vol. 73. - P. 151-158.

49. Immune system responders to nucleus pulposus cells: evidence for immune response in disc herniation / K. Murai, D. Sakai, Y. Nakamura et al. // European cells and materials. $-2010 .-$ Vol. 19. - P. 13-21.

50. Innate immunity and angiogenesis / S. Frantz, K.A. Vincent, O. Feron, R.A. Kelly / Circ. Res. - 2005. Vol. 96, № 1. - P. 15-26.

51. Transplantation of mesenchymal stem cells in a canine disc degeneration model / A. Hiyama, J. Mochida, T. Iwashina et al. // J. Orthop. Res. - 2008. - Vol. 26. - P. 589-600.

52. Wildner G. Autoimmune uveitis and antigenic mimicry of environmental antigens / Wildner G., Diedrichs-Mohring M. // Autoimmun. Rev. - 2004. - Vol. 3. - P. 383-387.

53. A longitudinal study on an autoimmune murine model of ankylosing spondylitis / T. Bardos, Z. Szabo, M. Czipri et al. // Ann. Rheum. Dis. - 2005. - Vol. 64. - P. 981-987.

54. Bobechko W.P. Auto-immune response to nucleus pulposus in the rabbit / W.P. Bobechko, C. Hirsch // J. Bone Jt Surg. - 1965. - Vol. 47B. - P. 574-80.

55. Marshall L.L. Chemical radiculitis. A clinical, physiological and immunological study / L.L. Marshall, E.R. Trethewie, C.C. Curtain // Clin. Orthop. - 1977. Vol. 129. - P. 61-67.

56. The inflammatory effect of nucleus pulposus. A possible element in the pathogenesis of low-back pain / R.F. McCarron, M.W. Wimpee, P.G. Hudkins, G.S. Laros // Spine. 1987. - Vol. 12. - P. 760-764.

57. Glycosphingolipid antibodies in serum in patients with sciatica / H. Brisby, F. Balague, D. Schafer et al. // Spine. 2002. - Vol. 27. - P. 380-386.

58. Immunophenotypic analysis of the inflammatory infiltrates in herniated intervertebral discs / S. Kawaguchi, T. Yamashita, K. Yokogushi et al. // Spine. - 2001. - Vol. 26. P. 1209-1214.
59. Martin D. Pathophysiology of lumbar disc degeneration: a review of the literature / D. Martin, M. Boxell, G. Malone // Neurosurg. Focus. - 2002. - Vol. 13, № 2. - P. 1-6.

60. Intervertebral disc cells as competent phagocytes in vitro: implications for cell death in disc degeneration / P. Jones, L. Gardner, J. Menage et al. // Arthritis Research \& Therapy. - 2008. - Vol. 10. http://arthritis-research.com/content/10/4/R86.

61. Expression of TRAIL and the death receptors DR4 and DR5 correlates with progression of degeneration in human intervertebral disks / H. Bertram, A. Nerlich, G. Omlor et al. // Modern. Pathology. - 2009. - Vol. 22. - P. 895-905.

62. Both endoplasmic reticulum and mitochondria are involved in disc cell apoptosis and intervertebral disc degeneration in rats / C.-Q. Zhao, Y.-H. Zhang, S.-D. Jiang et al. // Age (Dordrecht, Netherlands). - 2010. - Vol. 32, № 2. P. 161-177.

63. The occurrence and regional distribution of DR4 on herniated disc cells: a potential apoptosis pathway in lumbar intervertebral disc / L. Zhang., T. Niu, S.Y. Yang et al. // Spine. - 2008. - Vol. 33, №4. - P. 422-427.

64. Urban J.P.G. Cells of the intervertebral disc: making the best of a bad environment / J.P.G. Urban, S. Roberts // The Biochemist. - 2003. - Vol. 25. - P. 15-17.

65. Savill J. Recognition and phagocytosis of cells undergoing apoptosis / J. Savill // Br. Med. Bull. - 1997. - Vol. 53. P. 491-508.

66. Thetrigger to cell death determines the efficiency with which dying cells are cleared by neighbours / U.K. Wiegand, S. Corbach, A.R. Prescott et al. // Cell Death Differ. 2001. - Vol. 8. - P. 746.

67. Castillo E.C.G. A new role for chondrocytes as nonprofessional phagocytes. An in vitro study / E.C.G. Castillo, J.B. Kouri // Micro. Res. Tech. - 2004. - Vol. 64. - P. 269278.

68. Degeneration and regeneration of the intervertebral disc: lessons from development / L.J. Smith, N.L. Nerurkar, K.-S. Choi et al. // Disease Models \& Mechanisms. - 2011. Vol. 4. - P. 31-41.

69. Hunter C.J. Cytomorphology of notochordal and chondrocytic cells from the nucleus pulposus: a species comparison / C.J. Hunter, J.R. Matyas, N.A. Duncan // J. Anat. 2004. - Vol. 205. - P. 357-362.

70. Immunolocalization of phagocytic cells in normal and degenerated intervertebral discs / A.G. Nerlich, C. Weiler, J. Zipperer et al. // Spine. - 2002. - Vol. 27. - P. 2484-2490.

71. Fadok V.A. Clearance: the last and often forgotten stage of apoptosis / V.A. Fadok // J. Mammary Gland. Biol. Neoplasia. - 1999. - Vol. 4. - P. 203-211.

72. Roach H.I. Chondroptosis: a variant of apoptotic death / H.I. Roach, T. Aigner, J.B. Kouri // Apoptosis. 2004. - Vol. 9. - P. 265-277.

73. Bursch W. The autophagosomal-lysosomal compartment in programmed cell death / W. Bursch // Cell. Death Differ. - 2001. - Vol. 8. - P. 569-581.

74. Ultrastructural analysis on lumbar disc herniation using surgical specimens: role of neovascularization and macrophages in hernias / S. Kobayashi, A. Meir, Y. Kokubo et al. // Spine (Phila Pa 1976). - 2009. - Vol. 34, № 7. - P. 655-662.

75. Spontaneous Regression of Herniated Disc. Experimental Study / Kikuchi Taro, Nakamura Takafumi, Ikeda Takashi et al. // J. Orthop. \& Traum. - 2000. - Vol. 49, № 2. P. 515-519.

76. Kikuchi T., Nakamura T., Ikeda T. et al. Monocyte chemoattractant protein-1 in the intervertebral disc. A histologic experimental model // Spine. - 1998. - Iss. 15. Vol. 23, № 10. - P. 1091-1099.

77. Intervertebral disc cells produce tumor necrosis factor alpha, interleukin-1beta, and monocyte chemoattractant protein-1 immediately after herniation: an experimental study using a new hernia model / M. Yoshida, T. Nakamura, A. Sei et al. // Spine. - 2005. - Vol. 30, №1. - P. 55-61.

Получено 10.03.13 